\title{
Role of prophylactic midurethral sling in preventing post-operative stress urinary incontinence following repair of anterior vaginal wall prolapse
}

\author{
Nabendu Bhattacharjee, ${ }^{1}$ Sneha Tickoo, ${ }^{2}$ Apurba Mandal, ${ }^{2}$ Nabanita Dasgupta, ${ }^{2}$ \\ Krishnendu Goswami, ${ }^{2}$ Anubhati Nag, ${ }^{2}$ Shibram Chattapadhyay ${ }^{2}$
}

Keywords: Anterior compartment prolapse, post-operative, stress urinary incontinence, prophylactic midurethral sling

\begin{abstract}
Objective: This study was conducted to find whether, among women without preoperative stress incontinence who underwent surgery for repair of anterior vaginal wall prolapse, the placement of a prophylactic midurethral mesh along with the prolapse correction surgery helped to reduce the incidence of post-operative stress urinary incontinence (POSUI).

Materials \& Methods: 145 women with anterior vaginal compartment prolapse were randomly assigned to receive either suitable corrective surgery for prolapse or corrective surgery along with concurrent placement of a prophylactic midurethral sling by a transobturator Prolene tape. The primary endpoint was urinary incontinence at three months and twelve months post surgery. Secondary outcomes included expected and unexpected adverse events.
\end{abstract}

Results: At three months follow up the symptoms of urinary incontinence and/or positive cough test did not differ significantly between the two groups. But at twelve months, both the symptoms of urinary incontinence (9.59\% versus $23.61 \%, p=0.025,95 \% \mathrm{Cl}=-$
$25.93 \%$ to $-2.11 \%$, CMLE OR =0.346) and positive cough test $(8.22 \%$ versus $25 \%, p=$ $0.007,95 \% \mathrm{Cl}=-28.60 \%$ to $-4.96 \%$, CMLE OR $=0.271$ ) were significantly lower in the study group compared to the control group. Expected and unexpected adverse events during operation and through the first year after surgery were comparable in both groups

Conclusion: Placement of a midurethral sling by a Prolene mesh at the time of prolapse repair surgery significantly reduces the incidence of POSUI in women who were continent preoperatively. For this, the transobturator tape method is safe and effective with a low rate of complications.

\footnotetext{
${ }^{1}$ Malda Medical College, Malda, West Bengal, India

${ }^{2}$ Nil Ratan Sircar Medical College, Kolkata, West Bengal, India
}

\section{Introduction}

Nearly $20 \%$ of women will have the need to undergo an operation for pelvic organ prolapse (POP) in her life span. ${ }^{1}$

Please cite this paper as: Bhattacharjee N, Tickoo S, Mandal A, Dasgupta N, Goswami K, Nag A, Chattapadhyay S. Role of prophylactic midurethral sling in preventing post-operative stress urinary incontinence following repair of anterior vaginal wall prolapse. Proc Obstet Gynecol. 2017;7(1): Article 6 [ 14 p.]. Available from: http://ir.uiowa.edu/pog/ Free full text article.

Corresponding author: Professor Nabendu Bhattacharjee, AD 289 Rabindrapally, Krishnapur, Kolkata 700101, India. Email: drnabendu@gmail.com

Financial Disclosure: The authors report no conflict of interest.

Copyright: (c) 2017 Bhattacharjee et al. This is an open-access article distributed under the terms of the Creative Commons Attribution License, which permits unrestricted use, distribution, and reproduction in any medium, provided the original author and source are credited. 
Another common problem among women is lower urinary tract abnormalities including incontinence which is common in women with high grade anterior compartment prolapse. Stress urinary incontinence (SUI) is characterized by involuntary passage of urine when the intravesical pressure rises higher than the pressure that the urethral closure mechanism can withstand, for example during coughing or sneezing. It is one of the most common causes of incontinence in women, with a peak incidence between 45 and 49 years of age. ${ }^{2}$ Risk factors for the development of stress urinary incontinence include childbirth; especially when the deliveries are by vaginal route compared to that of cesarean section. $^{3}$

Vaginal birth also predisposes a woman to develop pelvic organ prolapse. It is unsurprising therefore, that the two conditions frequently co-exist. The basic pathophysiology of both conditions is the same; laxity of support structures leads to loss of urethral resistance in one and prolapse in the other. It was found that previously continent women, who underwent a repair operation for anterior compartment prolapse such as cystocele and/or urethrocele, were at increased risk of emergent postoperative stress urinary incontinence (POSUI). Several studies have reported that the incidence of POSUI varies from $11 \%$ to $47 \% .^{4-7}$ Stress urinary incontinence, symptomatic or occult, which was absent preoperatively, may occur following anterior wall repair. No method is $100 \%$ accurate in detecting occult SUI and/or predicting development of post-operative SUI in women with POP. ${ }^{8-10}$ Simple clinical tests (such as, repositioning the prolapse using a pessary and a Pyridium pad test ${ }^{11}$ or a one-week ambulatory home pessary trial ${ }^{12}$ ) can be used to find out if occult urinary incontinence exists or not. As a measure against this unwanted complication i.e. POSUI, studies are being carried out on the effectiveness of a concomitant procedure along with the primary corrective surgery for POP. However, some authors advocate placement of a suburethral sling by systematic approach, taking into account the patients' variables and their own goals of therapy. ${ }^{13-16}$ Several studies have been conducted to assess the benefits and effects of a prophylactic sling surgery. Various studies have evaluated this in the context of abdominal surgery, for example, Burch colposuspension $^{7,8}$ and vaginal procedures, such as, transvaginal tape ${ }^{18-21}$ and transobturator tape ${ }^{22}$ approach. To the best of our knowledge, no such study has been conducted in India. This study evaluates the benefits and side effects of prophylactic midurethral sling placement during repair of anterior compartment prolapse.

\section{Aims and objectives}

This study aimed to find whether, placement of a prophylactic midurethral sling helped to reduce the incidence of post-operative stress urinary incontinence (POSUI) in women without pre-operative stress incontinence of any kind (occult or overt) who underwent surgery for repair of anterior vaginal wall prolapse. 


\section{Materials and methods}

This prospective randomized comparative trial $(\mathrm{RCT})$ was carried out between January, 2013 and December, 2014 , at a urogynecology referral center in Kolkata, India. One hundred and sixty six women who attended our Out Patients Department with signs and symptoms of anterior vaginal compartment prolapse (Stage II or greater cystocele), were scheduled for corrective surgery and fulfilled the eligibility criteria were assessed for enrolment in the study. Women who fulfilled the eligibility criteria on the basis of the interview and clinical examination (examined by resident doctors under the supervision of the consultant-in-charge) were counseled in the simplest language of their understanding, about the nature of the illness and the surgical procedure according to United States Food and Drug Administration (U.S. FDA) guidelines. ${ }^{23}$ The additional sling procedure along with the benefits as well as adverse effects were explained. Written informed consents were obtained from willing participants.

After undergoing thorough exclusion criteria 145 women were included in the study. Exclusion criteria were (a) symptomatic stress urinary incontinence, (b) positive cough stress test on admission, (c) contraindication for mid-urethral sling, such as, prior urethral/bladder neck operation, (d) women planning pregnancy within one year after operation, (e) medical illness requiring hospitalization on two or more occasions during the last one year, ( $f$ ) previous surgery for POP, (g) post hysterectomy POP and unwillingness to participate. The control group was assigned to receive the corrective surgery for prolapse while the sling group received the primary corrective surgery along with concurrent placement of a prophylactic midurethral sling by transobturator tape (TOT). A computer-generated randomization protocol divided the participants into two groups having 73 women in the study group (group A) and 72 in the control group (group B). The treatment allocation was concealed in opaque sequentially numbered envelopes which were deposited at the operation theatre and the surgeons doing the operations collected the corresponding sealed envelope directly from the operation theatre sister-in-charge just before performing the operation and the procedure was completed as per code. The control group was assigned to receive the suitable corrective surgery for prolapse while the sling group received the primary corrective surgery along with concurrent placement of a prophylactic midurethral sling by transobturator tape. To avoid surgical bias as much as possible, all the procedures (sling and control group) were carried out by five members of a single surgical team. All surgeries were performed under spinal anesthesia. Standard technique for anterior colporrhaphy was performed with two layer repair of endopelvic fascial defect. Posterior defects were repaired in two layers and included repair of relaxed perineal body and rectocele. The patients who were assigned to receive the prophylactic midurethral sling (sling group) underwent TOT procedure with a Prolene mesh of size $9 \times 1.5 \mathrm{cms}$ with center measuring $2 \mathrm{cms}$ wide $\times 2.5 \mathrm{cms}$ across, placed over the mid portion of the urethra. Intra-operative difficulties 
and complications were noted and recorded. The post-operative course of all patients was assessed and recorded. The urinary catheter was removed for all patients after 24-28 hours. All patients who did not have any post-operative complications were discharged on postoperative day five.

The primary end point of the study was stress urinary incontinence which was identified by a positive cough stress test, symptoms of or treatment for urinary incontinence, at three and twelve months. Secondary outcomes included serious adverse events, expected complications typical of Prolene mesh and unexpected non-serious adverse events.

According to the outcomes following vaginal prolapse repair and midurethral sling trial, ${ }^{18}$ the incidence of postoperative stress urinary incontinence in women who were not given a prophylactic midurethral sling was $43 \%$ (compared to $18 \%$ in the other group) at 12 months follow up. This 25\% difference in the incidence of postoperative stress urinary incontinence between the concomitant prophylactic midurethral sling group and the control group ( $18 \%$ vs. $43 \%)$, was used to calculate the sample size for our study. The minimum sample size was calculated as 122, with 61 subjects in each arm, setting alpha error at 0.05 with a power of 80 , based on standard estimate with continuity correction (Fleiss, Statistical methods for Rates and Proportions). Before analyses a self-regulating second researcher double checked all data which was subsequently analyzed using Open Source Epidemiologic Statistics for
Public Health (Dean AG, Sullivan KM, Soe MM. OpenEpi: Open Source Epidemiologic Statistics for Public Health, www.OpenEpi.com, version 3.03, updated on 2014/09/22). The statistical calculations included independent " $\mathrm{t}$ " tests, mid-p exact tests, and conditional maximum likelihood estimate of odds ratio with confidence limits. The study was approved by the Institutional Ethical Committee as required by Indian law.

\section{Results}

One hundred sixty six women were assessed initially for eligibility criteria. Of these, 21 women were excluded from the study due to, either not fulfilling the criteria for inclusion $(n=13)$ or refusal for participation $(n=08)$. Randomization was done with 145 patients placed into two groups having 73 in the study group (Group A) and 72 in the control group (Group B). The control group was assigned to receive the corrective surgery for prolapse while the sling group received the primary corrective surgery along with concurrent placement of a prophylactic midurethral sling by a transobturator tape. Subsequently, 12 patients were lost during follow up post operatively (five from study group and seven from the control group). As we adopted the intention to treat principle for trial analysis, all patients were analyzed according to allocation treatment (Figure 1). Participants who were missing components of the compound end point were assumed to have had symptoms of incontinence and positive cough test.

Demographically, the patients in both groups were comparable in respect to 
age, parity, body mass index, socioeconomic and educational standard, menstrual status and grade of cystocele (Table 1). From Table 2, it is evident that the types of surgical procedures for POP in the two groups were comparable.

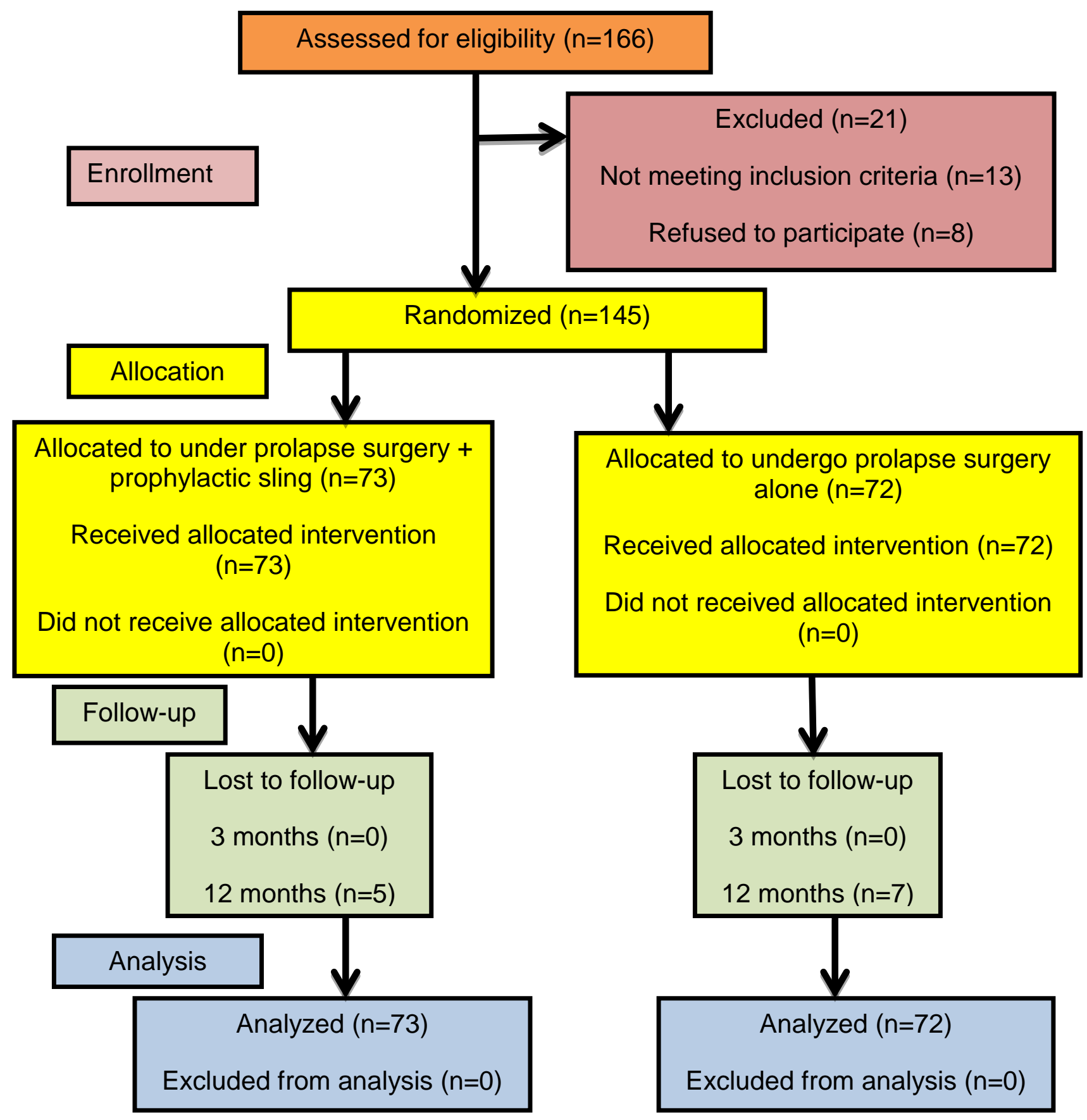

Figure 1: Patients' flow through chart 
Table 1: Demographic profile

\begin{tabular}{|c|c|c|c|}
\hline Characteristics & Study group & Control group & $P$ value \\
\hline & $(n=73)$ & $(n=72)$ & (95\% CI of difference) \\
\hline Age in years (mean $\pm s d \#)$ & $53.86 \pm 8.91$ & $55.75 \pm 9.36$ & $0.215^{1}(-4.889$ to 1.109$)$ \\
\hline Body mass index & $22.19 \pm 1.62$ & $22.08 \pm 1.53$ & $0.675^{1}(-0.407$ to 0.627$)$ \\
\hline \multicolumn{4}{|l|}{ Parity } \\
\hline Para 1 to 3 & $51(69.86 \%)$ & $52(72.22 \%)$ & $0.758^{2}(-12.40$ to 17.1$)$ \\
\hline Para 4 or more & $22(30.14 \%)$ & $20(27.78 \%)$ & \\
\hline \multicolumn{4}{|l|}{ Socio-economic status } \\
\hline Above poverty line & $12(16.44 \%)$ & $10(13.89 \%)$ & $0.6782(-9.116$ to 14.210$)$ \\
\hline Below poverty line & $61(83.56 \%)$ & $62(86.11 \%)$ & \\
\hline \multicolumn{4}{|l|}{ Educational Status } \\
\hline Illiterate & $15(20.55 \%)$ & $17(23.61 \%)$ & $0.663^{2}$ \\
\hline Primary school & $39(53.42 \%)$ & $41(56.94 \%)$ & $0.674^{2}$ \\
\hline Secondary school & $15(20.55 \%)$ & $12(16.67 \%)$ & $0.558^{2}$ \\
\hline Higher education & $4(5.48 \%)$ & $2(2.78 \%)$ & $0.455^{2}$ \\
\hline \multicolumn{4}{|l|}{ Menstrual status } \\
\hline Premenopausal & $15(20.55 \%)$ & $15(20.55 \%)$ & $0.558^{2}(-8.77$ to 16.53$)$ \\
\hline Postmenopausal & $58(35.62 \%)$ & $60(83.33 \%)$ & \\
\hline \multicolumn{4}{|l|}{ Grade of cystocele } \\
\hline Grade II & $47(64.38 \%)$ & $44(61.11 \%)$ & $0.688^{2}$ \\
\hline Grade III & $26(35.63 \%)$ & $28(38.89 \%)$ & $(-12.46$ to 19.00$)$ \\
\hline
\end{tabular}

While symptoms of urinary incontinence, positive cough test and treatment for incontinence were greater in the control group than those in the study (prophylactic TOT) group at three months, the figures were not statistically significant (Table 3). However both symptoms of urinary incontinence (9.59\% versus $23.61 \%, p=0.025,95 \%$ $\mathrm{Cl}=-25.93 \%$ to $-2.11 \%$, CMLE OR $=0.346)$ and positive cough test $(8.22 \%$ versus $25 \%, \mathrm{p}=0.007,95 \% \mathrm{Cl}=-$
$28.60 \%$ to $-4.96 \%$, CMLE OR $=0.271$ ) were significantly lower at 12 months in the study group. Expected and unexpected adverse events (secondary outcomes) during operation and through the first year after surgery were comparable in both groups. Three women in the study group needed urethral dilation for post-operative voiding difficulty and one woman had mesh erosion, the numbers were statistically insignificant (Table 4). 
Table 2: Surgical procedures performed for POP.

\begin{tabular}{|c|c|c|c|}
\hline Type of operation & Study group & Control group & P value* \\
\hline & $(\mathrm{n}=73)$ & $(n=72)$ & $(95 \% \mathrm{CI})$ \\
\hline Anterior colporrhaphy & $04(5.48 \%)$ & $05(6.94 \%)$ & $0.731(-9.322$ to 6.392$)$ \\
\hline Vaginal hysterectomy + anterior colporrhaphy & $34(46.57 \%)$ & $29(40.28 \%)$ & 0.451 (-9.804 to 22.40$)$ \\
\hline Anterior colporrhaphy + colpoperineorrhaphy & $09(12.33 \%)$ & $07(9.72 \%)$ & $0.630(-7.577$ to 12.79$)$ \\
\hline Vaginal hysterectomy + anterior colporrhaphy+ & $26(35.62 \%)$ & $31(43.06 \%)$ & $0.366(-23.30$ to 8.418$)$ \\
\hline Colpoperineorrhaphy & & & \\
\hline
\end{tabular}

\section{Discussion}

With the life expectancy of women in India having risen to 68.5 years,,$^{24}$ it is natural to expect that we would be facing more patients with complaints of pelvic organ prolapse and stress urinary incontinence. Moreover, previously continent women who undergo surgical repair of anterior compartment prolapse may be at increased risk of developing post-operative stress urinary incontinence (POSUI). Thus, it has been suggested that a concomitant procedure may be added along with the primary corrective surgery of anterior compartment prolapse for prevention of post-operative stress incontinence. This prophylactic procedure, a transobturator synthetic mesh placement, was adopted in 73 women with various types of surgeries for POP in our RCT with a control group of 72 women.

The average age of the women in our study, $53.86 \pm 8.91$ years for the study group and $55.75 \pm 9.36$ years for the control group, was lower compared to that in the study by Wei et al., ${ }^{18} 63.4 \pm$ 10.8 in the sling group and $62.2 \pm 10.2$ in the control group. Our study also had a very different profile in terms of socioeconomic status with $83.56 \%$ of cases and $86.11 \%$ of controls being below the poverty line compared to western studies. Similarly, educational status of the women in our study differed significantly from that in the study by Wei et al. ${ }^{18}$ While their study had $37 \%$ and $44 \%$ women completing high school or less in the sling and control group respectively, our study had $21.03 \%$ (in study group) and $19.45 \%$ (in control group) women having post primary education. In our study, there were no patients with stage 4 cystocele. This was in contrast to the study by Wei et al. ${ }^{18}$ where $08 \%$ and $10 \%$ of the sling and the control group had Stage 4 cystocele and by Brubaker et al. ${ }^{7,8}$ where $21 \%$ of the Burch group and $17 \%$ of the control group had stage 4 cystocele. 
Table 3: Primary outcomes at three and twelve months follow-up.

\begin{tabular}{|c|c|c|c|c|}
\hline Outcome & Study group & Control group & P Value \# & OR* \\
\hline & $(\mathrm{n}=73)$ & $(n=72)$ & ( $95 \%$ CI ) & ( 95\% CI ) \\
\hline \multicolumn{5}{|l|}{$\begin{array}{l}\text { End point at three months } \\
\text { (12 to14 weeks) }\end{array}$} \\
\hline Symptoms of incontinence & $1(1.37 \%)$ & 5 (6.94\%) & $\begin{array}{c}0.115 \\
(-12.02 \% \text { to } 0.87 \%)\end{array}$ & $\begin{array}{c}0.188 \\
(0.008 \text { to } 1.40)\end{array}$ \\
\hline Positive cough test & 0 & $3(4.17 \%)$ & $\begin{array}{c}0.120 \\
\text { (-8.78\% to } 0.45 \%)\end{array}$ & 0.0 (0.0 to 1.67$)$ \\
\hline Treatment for incontinence & $1(1.37 \%)$ & $5(6.94 \%)$ & $\begin{array}{c}0.115 \\
(-12.02 \% \text { to } 0.87 \%)\end{array}$ & $\begin{array}{c}0.188 \\
(0.008 \text { to } 1.40)\end{array}$ \\
\hline \multicolumn{5}{|l|}{ End point at twelve months: } \\
\hline \multicolumn{5}{|l|}{ A. ITT analysis ${ }^{1}$} \\
\hline Symptoms of incontinence & $2+5 \bullet(9.59 \%)$ & $10+7 \bullet(23.61 \%)$ & $\begin{array}{c}0.025 \\
(-25.93 \% \text { to }-2.11 \%)\end{array}$ & $\begin{array}{c}0.346 \\
\text { (0.125 to } 0.881) \\
\end{array}$ \\
\hline Positive cough test & $1+5 \bullet(8.22 \%)$ & $11+7 \bullet(25 \%)$ & $\begin{array}{c}0.007 \\
(-28.60 \% \text { to }-4.96 \%)\end{array}$ & $\begin{array}{c}0.271 \\
(0.093 \text { to } 0.713) \\
\end{array}$ \\
\hline \multicolumn{5}{|l|}{ B. PP analysis ${ }^{2}$} \\
\hline Symptoms of incontinence & $2 / 68(2.94 \%)$ & 10/65 (15.38\%) & $\begin{array}{c}0.014 \\
(-22.09 \% \text { to }-2.80 \%)\end{array}$ & $\begin{array}{c}0.169 \\
(0.024 \text { to } 0.727)\end{array}$ \\
\hline Positive cough test & $1 / 68(1.47 \%)$ & 11/65 (16.92\%) & $\begin{array}{c}0.002 \\
(-25.01 \% \text { to }-5.90 \%)\end{array}$ & $\begin{array}{c}0.074 \\
(0.003 \text { to } 0.456)\end{array}$ \\
\hline
\end{tabular}

\# Mid-P exact. $\quad$ * Conditional maximum likelihood estimate of Odds Ratio.

${ }^{1}$ Intention to treat principle. ${ }^{2}$ Per protocol. $\quad$ Lost to follow up cases.

In view of varying degrees of uterine prolapse and due to most patients wishing against retention of their uterus, the majority of the women in our study underwent hysterectomy along with the prolapse repair; $82.19 \%$ in the sling group and $83.34 \%$ in the control group respectively. In the study by Wei et al., ${ }^{18}$ however, only $50 \%$ and $48 \%$ of the sling and the control group underwent concomitant hysterectomy respectively. Additionally $38 \%$ of the women from both groups in their study had had previous hysterectomy. In our study,
$47.95 \%$ of the women in the sling group and $52.78 \%$ in the control group had repair of posterior compartment prolapse also, which was similar to the study by Wei et al. ${ }^{18}$ where $45 \%$ and $47 \%$ of women from the sling and control group respectively underwent posterior repair additionally.

The study conducted by Brubaker et al. ${ }^{7,8}$ evaluated abdominal sacrocolpopexy with additional Burch colposuspension for urethral support. The study conducted by Wei et al. ${ }^{18}$ 
evaluated the same while using transvaginal tape (TVT) for midurethral support. This was similar to the procedure evaluated by Meschia et al. ${ }^{21}$ and Gordan D et al. ${ }^{20}$ In our study we utilized the transobturator polypropylene mesh as midurethral sling. This technique of sling placement was similar to the procedure undertaken by Araki et al. ${ }^{22}$ who performed transobturator midurethral sling placement only in patients with symptomatic SUI and/or positive cough test along with repair of POP by polypropylene mesh.

Table 4: Expected and unexpected adverse events during operation and through first year after surgery.

\begin{tabular}{|c|c|c|c|c|}
\hline Outcome & $\begin{array}{l}\text { Study } \\
\text { group }\end{array}$ & $\begin{array}{l}\text { Control } \\
\text { group }\end{array}$ & P Value \# & CMLE OR* \\
\hline & $(n=73)$ & $(n=72)$ & $(95 \%$ CI ) & ( $95 \%$ CI ) \\
\hline $\begin{array}{l}\text { Major bleeding or vascular } \\
\text { complication }\end{array}$ & $2(2.74 \%)$ & $4(5.56 \%)$ & $\begin{array}{l}0.435 \\
(-9.30 \% \text { to3.67\%) }\end{array}$ & $\begin{array}{l}0.481 \\
(0.06 \text { to } 2.80)\end{array}$ \\
\hline Urethral or bladder injury & $2(2.74 \%)$ & $1(1.39 \%)$ & $\begin{array}{l}0.630 \\
(-3.27 \% \text { to } 5.97 \%)\end{array}$ & $\begin{array}{l}1.99 \\
(0.15 \text { to } 59.77)\end{array}$ \\
\hline Operative site infection & $1(1.37 \%)$ & $1(1.39)$ & $\begin{array}{l}0.993 \\
(-3.82 \% \text { to } 3.78 \%)\end{array}$ & $\begin{array}{l}0.986 \\
(0.02 \text { to } 38.97)\end{array}$ \\
\hline Urinary tract infection & $2(2.74 \%)$ & $3(4.17 \%)$ & $\begin{array}{l}0.672 \\
(-7.37 \% \text { to } 4.52 \%)\end{array}$ & $\begin{array}{l}0.6498 \\
(0.07 \text { to } 4.49)\end{array}$ \\
\hline $\begin{array}{l}\text { Post-operative urinary retention } \\
\text { following catheter removal }\end{array}$ & $6(8.22 \%)$ & $7(9.72 \%)$ & $\begin{array}{l}0.7619 \\
(-10.8 \% \text { to } 7.80 \%)\end{array}$ & $\begin{array}{l}0.833 \\
(0.25 \text { to } 2.70)\end{array}$ \\
\hline Incomplete bladder emptying & $3(4.11 \%)$ & $1(1.39 \%)$ & $\begin{array}{l}0.377 \\
(-2.57 \% \text { to } 8.02 \%)\end{array}$ & $\begin{array}{l}3.02 \\
(0.31 \text { to } 81.16)\end{array}$ \\
\hline $\begin{array}{l}\text { Postoperative voiding difficulty } \\
\text { requiring urethral dilatation+ }\end{array}$ & $\begin{array}{l}3 / 68 \\
(4.41 \%)\end{array}$ & $0 / 65$ & $\begin{array}{l}0.131 \\
(-0.47 \% \text { to } 9.29 \%)\end{array}$ & undefined \\
\hline Mesh erosion+ & $\begin{array}{l}1 / 68 \\
(1.47 \%)\end{array}$ & $0 / 65$ & $\begin{array}{l}0.511 \\
(-1.39 \% \text { to } 4.33 \%)\end{array}$ & undefined \\
\hline
\end{tabular}

* Conditional maximum likelihood estimate of Odds Ratio. \# \#id-P exact

+ Per protocol analysis was done considering the nature of complication.

In our study, $6.94 \%$ of the patients who did not undergo the additional midurethral sling placement developed POSUl at three months following surgery in comparison to only $1.37 \%$ of those who underwent concomitant prophylactic midurethral sling placement. However, this difference was 
not statistically significant This was in contrast to the findings of Wei et al. ${ }^{18}$ who reported a urinary incontinence rate of $23.6 \%$ in the sling group and $49.4 \%$ in the sham group (adjusted odds ratio, $95 \% \mathrm{Cl}, 0.19$ to $0.50 ; \mathrm{p}<0.001)$. The trial by Brubaker et al. ${ }^{7,8}$ also showed a significant difference with $23.8 \%$ (35 women) of the Burch group and $44.1 \%$ (67 women) of the control group meeting one or more criteria for stress incontinence $(P<0.001)$. This difference at 3 months between our study and their study could have been due to the higher stage of pelvic organ prolapse in the above studies compared to ours. Presence of incontinence and/or positive cough test at 12 months following surgery in the group of women with prophylactic concomitant TOT placement were significantly lower compared to those in control group. The results of our study were similar to those found by Wei et al. ${ }^{18}$ who also reported a significant difference of SUI at 12 months post surgery ( $p<0.001)$. Brubaker et al. ${ }^{7,8}$ also showed that at 12 months, women who had an additional Burch colposuspension along with abdominal sacrocolpopexy had significantly lower rates of urinary incontinence $(p=0.02)$.

No patient in either group of our study had any serious adverse event during the surgery. The study conducted by Wei et al. ${ }^{18}$ reported similar outcome. Our study reported no difference in the rates of major bleeding and vascular complications $(p=0.435)$. In contrast, Wei et al. ${ }^{18}$ had a significantly higher rate of bleeding complications in the sling group $(p=0.03)$. Only two patients from our study had urethral or bladder injury during sling placement. Kuan-Hui
Huang et al. $^{25}$ in their study did not report any bladder injury or other complications that required laparotomy during concomitant TVT procedure along with primary surgery for pelvic organ prolapse. This was in contrast to Wei et al. ${ }^{18}$ who had a significant number of patients from the sling group with this complication. Their study utilized the transvaginal mesh in contrast to transobturator mesh which has a higher bladder perforation rate as reported by other authors. ${ }^{13-16}$

Our study did not report any significant difference between the two groups for incidence of urinary tract infection $(p=0.672)$. This was in contrast to the findings of the OPUS trial ${ }^{18}$ where the difference was significant $(p=0.008)$. The same trial also reported a significant incidence of incomplete bladder emptying $(p=0.01)$ in the sling group which was found only in three patients in our study $(p=0.377)$. None of the patients in our study required urethrolysis surgery in contrast to the findings of Wei et al. ${ }^{18}$ who did urethrolysis for persistent voiding dysfunction in sling group (4/165 versus $0 / 172, p=0.06)$. One patient from our sling group developed mesh erosion $(1.47 \%)$ and was successfully treated by excision of the eroded tape and repair of anterior vaginal wall in two layers. In the study conducted by Wei et al. ${ }^{18}$ no patient developed mesh erosion. Groutz et al. ${ }^{26}$ reported $3 \%$ incidence of erosion of the vaginal tape for treatment of occult stress urinary incontinence.

Our study had the limitation of only 145 subjects as the total duration of study was 24 months. While sample size calculations were performed and 
confirmed the number needed for each group, a larger sample size may give more significant results. Routine preoperative urodynamics for occult SUI was not performed on our patients. Our study did not assess pre and postoperative quality of life such as by pelvic floor distress questionnaires, etc. Also, our patients were followed up only for one year following the surgery.

To conclude, the placement of a midurethral Prolene mesh concomitantly during repair of anterior compartment prolapse significantly reduces the incidence of post-operative stress urinary incontinence in women who were continent preoperatively. For this, the transobturator tape method is safe and effective with a low rate of complications. Concomitant placement of a midurethral sling may prevent the need for a woman to undergo a second surgical procedure following the primary prolapse repair. More studies with larger sample sizes are required to evaluate for the long term efficacy and safety of prophylactic concomitant mesh placement in the mid portion of urethra during surgery for POP.

\section{Disclosure:}

The authors have no commercial or other conflicts of interest i.e. of financial or other nature. The authors also have no commercial affiliations to disclose.

\section{References}

1. Smith FJ, Holman CD, Moorin RE, Tsokos N. Lifetime risk of undergoing surgery for pelvic organ prolapse. Obstet Gynecol. 2010 Nov;116(5):1096100.

https://doi.org/10.1097/AOG.0b013e318 1f73729 PubMed PMID: 20966694.

2. Herzog AR, Fultz NH. Prevalence and incidence of urinary incontinence in community-dwelling populations. J Am Geriatr Soc. 1990 Mar;38(3):273-81. https://doi.org/10.1111/j.1532-

5415.1990.tb03504.x PubMed PMID: 2179368.

3. Hannestad YS, Rortveit G, Sandvik H, Hunskaar S; Norwegian EPINCONT study. Epidemiology of Incontinence in the County of Nord-Trøndelag.. A community-based epidemiological survey of female urinary incontinence: the Norwegian EPINCONT study. Epidemiology of Incontinence in the County of Nord-Trøndelag. J Clin Epidemiol. 2000 Nov;53(11):1150-7. https://doi.org/10.1016/S08954356(00)00232-8 PubMed PMID: 11106889.

4. Stanton SL, Hilton $\mathrm{P}$, Norton C, Cardozo L. Clinical and urodynamic effects of anterior colporrhaphy and vaginal hysterectomy for prolapse with and without incontinence. $\mathrm{Br} \mathrm{J}$ Obstet Gynaecol. 1982 Jun;89(6):459-63. https://doi.org/10.1111/j.14710528.1982.tb03637.x PubMed PMID: 7082603.

5. Al-Mandeel $\mathrm{H}$, Ross $\mathrm{S}$, Robert $\mathrm{M}$, Milne J. Incidence of stress urinary incontinence following vaginal repair of pelvic organ prolapse in objectively continent women. Neurourol Urodyn. 2011 Mar;30(3):390-4. https://doi.org/10.1002/nau.20947 PubMed PMID: 21284021. 
6. Kanasaki $\mathrm{H}$, Oride $\mathrm{A}$, Mitsuo $\mathrm{T}$, Miyazaki K. Occurrence of pre- and postoperative stress urinary incontinence in 105 patients who underwent tension-free vaginal mesh surgery for pelvic organ prolapse: a retrospective study. ISRN Obstet Gynecol. 2014 Feb 6;2014:643495. https://doi.org/10.1155/2014/643495

PubMed PMID: 24653836; PubMed Central PMCID: PMC3933322.

7. Brubaker L, Cundiff GW, Fine $P$, Nygaard I, Richter HE, Visco AG, Zyczynski $\mathrm{H}$, Brown MB, Weber AM; Pelvic Floor Disorders Network.. Abdominal sacrocolpopexy with Burch colposuspension to reduce urinary stress incontinence. N Engl J Med. 2006 Apr 13;354(15):1557-66. Erratum in: N Engl J Med. 2016 Jun 9;374(23):2297-8. https://doi.org/10.1056/NEJMoa054208

PubMed PMID: 16611949.

8. Brubaker L, Nygaard I, Richter HE, Visco A, Weber AM, Cundiff GW, Fine P, Ghetti C, Brown MB. Two-year outcomes after sacrocolpopexy with and without Burch to prevent stress urinary incontinence. Obstet Gynecol. 2008 Jul;112(1):49-55.

https://doi.org/10.1097/AOG.0b013e318 1778d2a PubMed PMID: 18591307; PubMed Central PMCID: PMC2614233.

9. Liang $\mathrm{CC}$, Chang $\mathrm{YL}$, Chang $\mathrm{SD}$, Lo TS, Soong YK. Pessary test to predict postoperative urinary incontinence in women undergoing hysterectomy for prolapse. Obstet Gynecol. 2004 Oct;104(4):795-800. https://doi.org/10.1097/01.AOG.000014 0689.90131.01 PubMed PMID: 15458904.
10. Nishizawa O, Ichino $M$, Ishikawa $M$, Tanabe T, Suzuki H, Saito T, Imamura $\mathrm{T}$, Ishizuka O. Videourodyanamic examination and tension-free vaginal mesh/transobturator tape surgery. Low Urin Tract Symptoms. 2012 Mar;4 Suppl 1:110-3. https://doi.org/10.1111/j.17575672.2011.00120.x PubMed PMID: 26676709.

11. Reena C, Kekre AN, Kekre N. Occult stress incontinence in women with pelvic organ prolapse. Int J Gynaecol Obstet. $\quad 2007 \quad$ Apr;97(1):31-4. https://doi.org/10.1016/i.ijgo.2006.12.01 1 PubMed PMID: 17291508.

12. Chughtai B, Spettel S, Kurman J, De E. Ambulatory pessary trial unmasks occult stress urinary incontinence. Obstet Gynecol Int. 2012;2012:392027. https://doi.org/10.1155/2012/392027 PubMed PMID: 21949665; PubMed Central PMCID: PMC3178112.

13. Chermansky CJ, Krlin RM, Winters JC. Selective management of the urethra at time of pelvic organ prolapse repair: an assessment of postoperative incontinence and patient satisfaction. $\mathrm{J}$ Urol. 2012 Jun;187(6):2144-8. https://doi.org/10.1016/i.juro.2012.01.06 5 PubMed PMID: 22503013.

14. Wu MP, Long CY, Liang CC. Staged or concomitant surgery for correcting pelvic organ prolapse and stress urinary incontinence. Incont Pelvic Floor Dysfunct 2010;4(4):93-98.

15. Fatton B. Is there any evidence to advocate SUI prevention in continent women undergoing prolapse repair? An overview. Int Urogynecol J Pelvic Floor Dysfunct. 2009 Feb;20(2):235-45. https://doi.org/10.1007/s00192-0080734-4 PubMed PMID: 18936868. 
16. Togami JM, Chow D, Winters JC. To sling or not to sling at the time of anterior vaginal compartment repair. Curr Opin Urol. 2010 Jul;20(4):269-74. https://doi.org/10.1097/MOU.0b013e328 33a8a07 PubMed PMID: 21475069.

17. Twiss C, Triaca V, Raz S. Re: Reevaluating occult stress incontinence. Eur Urol. 2007 Mar;51(3):850-1. https://doi.org/10.1016/i.eururo.2006.12. 005 PubMed PMID: 17421062.

18. Wei JT, Nygaard I, Richter HE, Nager $\mathrm{CW}$, Barber MD, Kenton K, Amundsen CL, Schaffer J, Meikle SF, Spino C; Pelvic Floor Disorders Network.. A midurethral sling to reduce incontinence after vaginal prolapse repair. $\mathrm{N}$ Engl $\mathrm{J}$ Med. 2012 Jun 21;366(25):2358-67. https://doi.org/10.1056/NEJMoa1111967 PubMed PMID: 22716974; PubMed Central PMCID: PMC3433843.

19. Futyma K, Miotła P, Bartuzi A, Winkler I, Lis E, Kulik-Rechberger B, Rechberger $T$. Does a midurethral sling inserted at the time of pelvic organ prolapse mesh surgery increase the rate of de novo OAB? A prospective longitudinal study. Ginekol Pol. 2014 Sep;85(9):652-7.

https://doi.org/10.17772/gp/557 PubMed PMID: 25322535.

20. Gordon D, Gold RS, Pauzner D, Lessing JB, Groutz A. Combined genitourinary prolapse repair and prophylactic tension-free vaginal tape in women with severe prolapse and occult stress urinary incontinence: preliminary results. Urology. 2001 Oct;58(4):547-50. http://dx.doi.org/10.1016/S00904295(01)01327-9 PubMed PMID: 11597536.
21. Meschia $M$, Pifarotti $P$, Spennacchio M, Buonaguidi A, Gattei U, Somigliana E. A randomized comparison of tensionfree vaginal tape and endopelvic fascia plication in women with genital prolapse and occult stress urinary incontinence. Am J Obstet Gynecol. 2004 Mar;190(3):609-13.

https://doi.org/10.1016/j.ajog.2003.09.02 7 PubMed PMID: 15041988.

22. Araki I, Haneda $\mathrm{Y}$, Mikami $\mathrm{Y}$, Takeda $M$. Incontinence and detrusor dysfunction associated with pelvic organ prolapse: clinical value of preoperative urodynamic evaluation. Int Urogynecol J Pelvic Floor Dysfunct. 2009 Nov;20(11):1301-6. https://doi.org/10.1007/s00192-0090954-2 PubMed PMID: 19597715.

23. Urogynecologic surgical mesh: update on serious complications associated with transvaginal placement of surgical mesh for pelvic organ prolapse: FDA Safety Communication, released July 13, 2011. http://www.fda.gov/MedicalDevices/Safe ty/AlertsandNotices/ucm262435.htm

24. GBD 2013 Mortality and Causes of Death Collaborators.. Global, regional, and national age-sex specific all-cause and cause-specific mortality for 240 causes of death, 1990-2013: a systematic analysis for the Global Burden of Disease Study 2013. Lancet. 2015 Jan 10;385(9963):117-71. https://doi.org/10.1016/S01406736(14)61682-2 PubMed PMID: 25530442; PubMed Central PMCID: PMC4340604.

25. Huang $\mathrm{KH}$, Kung FT, Liang $\mathrm{HM}$, Chen CW, Chang SY, Hwang LL. Concomitant pelvic organ prolapse surgery with TVT procedure. Int Urogynecol J Pelvic Floor Dysfunct. 2006 Jan;17(1):60-5. https://doi.org/10.1007/s00192-0051337-y PubMed PMID: 15965574. 
26. Groutz A, Gold R, Pauzner D, Lessing JB, Gordon D. Tension-free vaginal tape (TVT) for the treatment of occult stress urinary incontinence in women undergoing prolapse repair: a prospective study of 100 consecutive cases. Neurourol Urodyn. 2004;23(7):632-5.

https://doi.org/10.1002/nau.20068

PubMed PMID: 15382184. 